\title{
Effect of Body Mass Index on Primary Dysmenorrhea and Daily Activities in Adolescents
}

\author{
SOHEIR M. EL-KOSERY, Ph.D.*; NERMEEN T. MOSTAFA, M.Sc.* and HEBA H. YOSSEUF, Ph.D.** \\ The Department of Physical Therapy for Women's Health, Faculty of Physical Therapy, Cairo University* and \\ The Department of Obstetrics \& Gynecology, Faculty of Medicine, El-Minia University**
}

\begin{abstract}
Background: Primary dysmenorrhea is the most prevalent menstrual problem in young females, which affects their daily activities and quality of life. Although some studies have demonstrated an association between BMI and the incidence and severity of dysmenorrhea, this relationship is still controversial.

Aim of Study: To investigate the effect of body mass index on primary dysmenorrhea and daily activities in adolescents.

Subjects and Methods: A correlational study involved 100 adolescent girls, selected from Beni-Mazar Secondary School throughout the period from March 2019 to August 2019. Their age ranged from 16 to 25 years. Subjects were classified into 4 groups equally according to body mass index. Pain intensity was measured using numeric pain scale, pressure pain threshold using pressure algometer and daily activities using daily activities questionnaire.

Results: The study findings revealed that there was a significant difference in the numeric pain scale between groups $(p=0.001)$, there was a significant difference in pressure pain thresholds between groups $(p=0.0001)$ and there was no significant difference in the daily activities between groups $(p=0.17)$ except for school absenteeism and social activity there was a significant difference $(p=0.001),(p=0.006)$ respectively.

Conclusion: The difference in body mass index had an effect on primary dysmenorrhea; both obese and underweight subjects suffer from primary dysmenorrhea more than subjects with normal weight and overweight, there was no difference on daily activities except for school absenteeism and social activity had higher percentage in obese and underweight.
\end{abstract}

Key Words: Body mass index - Primary dysmenorrheaPressure pain threshold-Daily activities.

\section{Introduction}

PRIMARY Dysmenorrhea (PD) is defined as painful, spasmodic cramping in the lower abdomen,

Correspondence to: Dr. Soheir M. El-Kosery, The Department of Physical Therapy for Women's Health, Faculty of Physical Therapy, Cairo University just before and/or during menstruation, in the absence of any discernable macroscopic pelvic pathology. The onset of primary dysmenorrhea usually occurs in adolescence, at or shortly after (6-24 months) menarche. The onset of primary dysmenorrheic pain usually has a clear and predictable temporal pattern, beginning just before or at the start of menstruation. The pain typically lasts for $8-72 \mathrm{~h}$, is most severe during the first or second day of menstruation, and may radiate to the back and thighs. In addition, systemic symptoms such as nausea, vomiting, diarrhea, fatigue and insomnia frequently accompany the pain [1] .

Primary dysmenorrhea is caused by an increased production of prostaglandins in the menstruating uterus, resulting in endometrial ischemia, uterine contractions and increased sensitivity of nerve endings leading to pain [2].

Primary dysmenorrhea is the most prevalent menstrual problem in young females, which affects their daily activities and quality of life. It is also considered to be the most common cause of school absenteeism in young females [3] .

Heat, pain, and pressure pain thresholds on the abdomen and low back have also been shown to be significantly lower in women with PD during the menstrual phase as compared to menstruating women without PD [4].

There are various reports regarding the impact of Body Mass Index (BMI) on dysmenorrhea. As several studies have indicated, various physiological, cultural and psychological factors are involved in dysmenorrhea. Although some studies have demonstrated an association between BMI and the incidence and severity of dysmenorrhea, this relationship is still controversial [5]. 
As the existing data is inconclusive and insufficient to demonstrate the effects of BMI on primary dysmenorrhea, so the present study may help us to provide a better insight into the effect of BMI on primary dysmenorrhea and on daily activities in ad2olescent girls.

\section{Subjects and Methods}

Subjects: 100 adolescent girls (age: 16-25 years). They were selected from Beni-Mazar Secondary School for Girls from March 2019 to August 2019. All subjects with diagnosed cases of any chronic illness, secondary dysmenorrhea, of any pelvic pathology and subjects using any medications (including hormonal contraception) for at least last 2 months were excluded from the study. Subjects were assigned into 4 groups equally according to BMI Group (A) 25 females with BMI $<18.5 \mathrm{~kg} / \mathrm{cm}^{2}$ underweight, Group (B) 25 females with BMI of $18.5-24.9 \mathrm{~kg} / \mathrm{cm}^{2}$ normal, Group (C) 25 females with BMI of $25-29.9 \mathrm{~kg} / \mathrm{cm}^{2}$ overweight and Group (D) 25 females with BMI $>30 \mathrm{~kg} / \mathrm{cm}^{2}$ obese. All patients were given full explanation of the study procedures, and signed informed consents were obtained before participation. This study was approved by the Ethics Committee for Scientific Research of the Faculty of Physical Therapy, Cairo University. The history of subjects was taken to exclude secondary dysmenorrhea, pelvic pathology and any hormonal contraception which may affect the study.

Methods: Weight and height were measured on the health weight and height scale. Then, Body Mass Index (BMI) was calculated through the following equation: $\mathrm{BMI}=$ weight $(\mathrm{kg}) /$ height $^{2}$ $\mathrm{kg} / \mathrm{m}^{2}$ [6]. Subjects were classified into 4 groups (A, B, C \& D) according to their BMI.

1- Numeric pain rating scale: Arabic version of numeric pain rating scale was used to assess pain intensity for all participants in four groups. The respondents were required to select a number (0-10 integers) that best reflected the intensity of her pain. In NPRS, the 0 represented no pain, 1-3 indicated mild pain, 4-6 indicated moderate pain, while 7-10 indicated severe pain $\left[{ }^{7}\right]$.

2- Pressure pain threshold:A pressure algometer (Wagner FDK 20, Wagner Instruments, Greenwich, CT, USA); was used to measure pressure pain thresholds for all participants in four groups [8].

Assessment of pressure pain thresholds had been done when the participants were at their menstrual phase between day 1 and day 3 of menstrual cycle. They were instructed not to use any pain relief medications up to $4 \mathrm{~h}$ before the procedure. The examiner made two measurements for the dominant forearm extensor muscle to ensure that the subject understands the procedures. If there was any doubt, a third demonstration would be done. Alcohol gel was used to clean the areas to be evaluated. Following, the marked points were used to record PPTs in all time points for the PPT assessment; a $1-\mathrm{cm}^{2}$ pressure probe was positioned perpendicularly to the skin and pressed at a rate of $30 \mathrm{kPa} / \mathrm{s}$.

Six points were determined to evaluate the PPTs. Two measures had been collected for each area, with 30 s between point testing. PPT recording sites were marked out the abdomen around the umbilical scar and lumbar region as follows: Two measurements $4 \mathrm{~cm}$ from the umbilicus, bilaterally (points I and II), two other measurements $4 \mathrm{~cm}$ below the previous ones (points III and IV), a single measurement $4 \mathrm{~cm}$ from the lower margin of the umbilicus (point V) and another single measurement into the medial side of the lumbar region below the fifth lumbar vertebra, corresponding to S2-S4 (point VI) [9].

Participants were instructed to say "now" when they first felt pain due to the increased pressure. At this point, the algometer was immediately stopped and automatically recorded the amount of pressure applied prior to its cessation [8] .

3- Daily activities questionnaire: Daily activities questionnaire items were translated into Arabic language for all participants in four groups. It was used to assess the impact of dysmenorrhea on activities of daily living including self- care, physical activity, school attendance, sleep, social and recreational activities [10].

\section{Data analysis:}

MANOVA test was carried out for comparison of NPRS and PPT between groups. Tukey post hoc test was conducted for pairwise comparison. Chi squared test was carried out for comparison of daily activities affection between groups. The level of significance for all statistical tests was set at $p<0.05$. All statistical measures were performed through the Statistical Package for Social Studies (SPSS) version 25 for windows.

\section{Results}

1- General characteristics of the subjects: Comparing the general characteristics of the sub- 
jects of the four groups revealed that there was no significance difference between the four groups in the mean age and height $(p>0.05)$. However, there was a significant difference between the four groups in the mean weight and BMI $(p=0.0001)$ (Table 1).

2- Comparison of the Numeric Pain Rating Scale (NPRS) between group $A, B, C$, and $D$ : The mean \pm SD NPRS of group A, B, C, and D were $5.12 \pm 1.45,3.6 \pm 1.52,4.6 \pm 1.93$, and $5.44 \pm 1.44$ respectively. There was a significant difference in the NPRS between the four groups $(p=0.001)$ (Table 2).

3- Comparison of mean values of Pressure Pain Thresholds (PPTs) between the four groups ( $A, B$, $C$, and $D)$ : The mean \pm SD PPT of group A, B, C, and $\mathrm{D}$ were $4.67 \pm 0.74,7.5 \pm 1.11,6.17 \pm 1.24$, and $5.13 \pm 0.96 \mathrm{lb}$ respectively. There was a significant difference in the PPT between the four groups ( $p$ $=0.0001)($ Table 3$)$.
4- Effect of BMI on daily activities:

A- Personal care: There was no significant difference in the personal care affection between groups $(p=0.7)$ (Table 4$)$.

$B$ - Physical activities: There was no significant difference in the physical activities' affection between groups $(p=0.46)$ (Table 4$)$.

$C$ - Sleep: There was no significant difference in the sleep affection between groups $(p=0.17)$ (Table 4).

D- Daily activities: There was no significant difference in the daily activities between groups $(p=0.17)$ (Table 4).

E- School absenteeism: There was a significant difference in the school absenteeism between groups ( $p=0.001)$ (Table 4).

$F$-Social activity: There was a significant difference in the social activity affected between groups $(p=0.006)$ (Table 4).

Table (1): Descriptive statistics and ANOVA test for the mean age, weight, height and BMI of group $\mathrm{A}, \mathrm{B}, \mathrm{C}$, and D.

\begin{tabular}{|c|c|c|c|c|c|c|c|}
\hline & $\begin{array}{l}\text { Group A } \\
X \pm S D\end{array}$ & $\begin{array}{l}\text { Group B } \\
X \pm S D\end{array}$ & $\begin{array}{l}\text { Group C } \\
X \pm S D\end{array}$ & $\begin{array}{l}\text { Group D } \\
X \pm S D\end{array}$ & $\begin{array}{c}\text { F- } \\
\text { value }\end{array}$ & $\begin{array}{c}p- \\
\text { value }\end{array}$ & Sig. \\
\hline Age (years) & $16.96 \pm 0.84$ & $16.72 \pm 0.84$ & $16.64 \pm 0.86$ & $17 \pm 0.91$ & 1.04 & 0.37 & NS \\
\hline Weight (kg) & $46.18 \pm 3.74$ & $54.7 \pm 6.25$ & $68.94 \pm 4.05$ & $79.3 \pm 5.21$ & 224.17 & 0.0001 & S \\
\hline Height (cm) & $161.16 \pm 5.49$ & $160.6 \pm 5.43$ & $160 \pm 4.02$ & $158.24 \pm 4.15$ & 1.71 & 0.16 & NS \\
\hline BMI $\left(\mathrm{kg} / \mathrm{m}^{2}\right)$ & $17.75 \pm 0.55$ & $21.16 \pm 1.8$ & $26.92 \pm 1.1$ & $31.64 \pm 1.12$ & 625.99 & 0.0001 & S \\
\hline $\begin{array}{l}\text { : Mean. } \\
: \text { Standa }\end{array}$ & ion. & $\begin{array}{l}\text { NS } \\
\text { S }\end{array}$ & $\begin{array}{l}\text { Non Significa } \\
\text { Significant. }\end{array}$ & & & & \\
\hline
\end{tabular}

Table (2): Comparison of mean values of Numeric Pain Rating Scale (NPRS) between the four groups (A, B, C, and D).

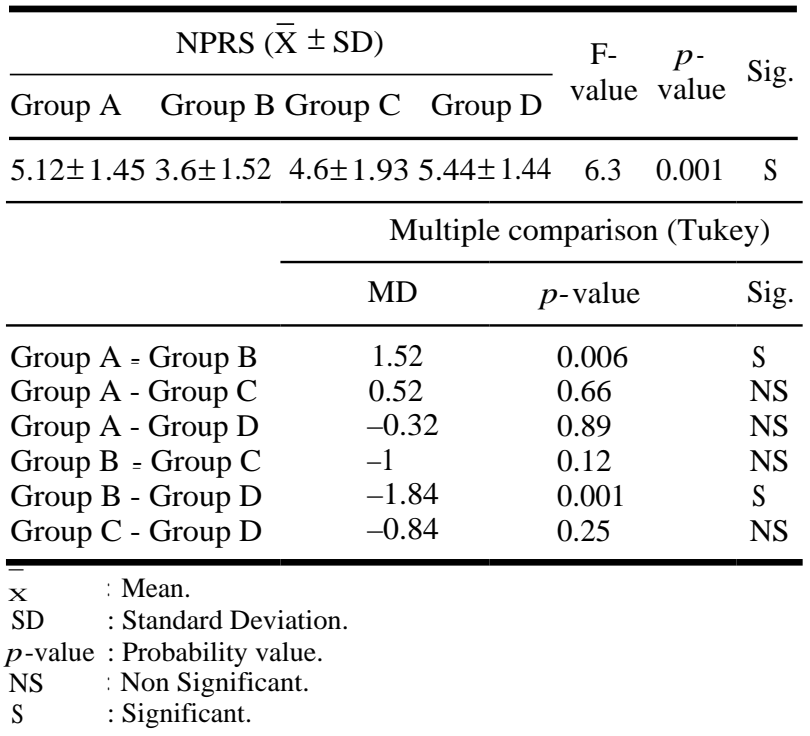

Table (3): Comparison of mean values of PPTs between the four groups (A, B, C, and D).

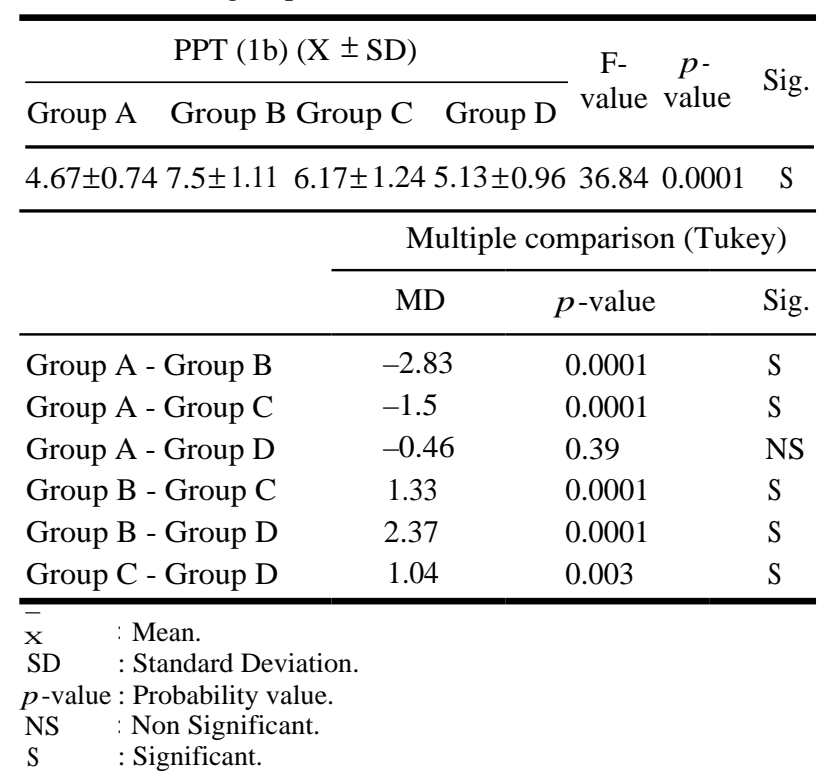


Table (4): The frequency distribution and chi squared test for comparison of daily activities affection between the four groups (A, B, C, and D).

\begin{tabular}{|c|c|c|c|c|c|c|c|}
\hline & Group A & Group B & Group C & Group D & $\%$ & $p$-value & Sig. \\
\hline \multicolumn{8}{|c|}{ Personal care: } \\
\hline Yes & $12(48 \%)$ & $13(52 \%)$ & $9 \quad(36 \%)$ & $11(44 \%)$ & 1.41 & 0.7 & NS \\
\hline No & $13(52 \%)$ & $12(48 \%)$ & $16(64 \%)$ & $14(56 \%)$ & & & \\
\hline \multicolumn{8}{|c|}{ Physical activities: } \\
\hline Yes & $21(84 \%)$ & $17(68 \%)$ & $19(76 \%)$ & $21(84 \%)$ & 2.56 & 0.46 & NS \\
\hline No & $4 \quad(16 \%)$ & $8 \quad(32 \%)$ & $6 \quad(24 \%)$ & $4 \quad(16 \%)$ & & & \\
\hline \multicolumn{8}{|l|}{ Sleep: } \\
\hline Yes & $18(72 \%)$ & $17(68 \%)$ & $16(64 \%)$ & $11(44 \%)$ & 4.92 & 0.17 & NS \\
\hline No & $7 \quad(28 \%)$ & $8 \quad(32 \%)$ & $9 \quad(36 \%)$ & $14(56 \%)$ & & & \\
\hline \multicolumn{8}{|c|}{ Daily activities: } \\
\hline Yes & $21(84 \%)$ & $17(68 \%)$ & $19(76 \%)$ & $23(92 \%)$ & 5 & 0.17 & NS \\
\hline No & $4 \quad(16 \%)$ & $8 \quad(32 \%)$ & $6 \quad(24 \%)$ & $2(8 \%)$ & & & \\
\hline \multicolumn{8}{|c|}{ School absenteeism: } \\
\hline Yes & $3 \quad(12 \%)$ & $1 \quad(4 \%)$ & $5 \quad(20 \%)$ & $12(48 \%)$ & 16.57 & 0.001 & S \\
\hline No & $22(88 \%)$ & $24(96 \%)$ & $20(80)$ & $13(52 \%)$ & & & \\
\hline \multicolumn{8}{|c|}{ Social activity: } \\
\hline Yes & $21(84 \%)$ & $12(48 \%)$ & $18(72 \%)$ & $22(88 \%)$ & 12.32 & 0.006 & $\mathrm{~S}$ \\
\hline No & $4 \quad(16 \%)$ & $13(52 \%)$ & $7 \quad(28 \%)$ & $3 \quad(12 \%)$ & & & \\
\hline
\end{tabular}

\section{Discussion}

Primary dysmenorrhea is one of the most frequent gynecological diseases, manifested by spasmodic cramping in the lower abdomen during menstrual period without any organic pelvic lesions [11].

Various studies reflect that age, parity, family history, use of oral contraceptive pills, smoking, stress, exercise, dietary habits and Body Mass Index (BMI) can affect PD. But the data regarding the effects of BMI on PD is still controversial [2], so this study was carried out to investigate the effect of Body Mass Index (BMI) on primary dysmenorrhea and daily activities in adolescents.

\section{Regarding the effect of BMI on pain:}

The study findings revealed that there was a significant effect of the difference in BMI on primary dysmenorrhea; both obese and underweight groups had high pain intensity and low pressure pain threshold than normal weight and overweight groups.

Also, Kaur et al., [12] found a statistical significant relation between low BMI and high BMI with severe dysmenorrhea $(p<0.0028)$. They concluded that severity of dysmenorrhea has significant relation with BMI (underweight and overweight) in adolescent girl.
Rafique and Al-Sheikh, [2] indicated that UW females are at a higher risk of having PD. They concluded that a higher prevalence of moderate and severe dysmenorrhea in UW as compared to the OB subjects.

Also, Hong et al., [13] stated that there was a U-shaped association was revealed between dysmenorrhea and BMI, revealing a higher risk of dysmenorrhea for both underweight and obese women. Maintaining a healthy weight over time may be important for women to have pain-free periods.

Snehalata et al., [14] provided a positive relationship between PD and increased BMI and demonstrated that severity of PD was increased by gaining weight and increasing BMI in their subjects, showed that there was a relationship between body mass composition and primary dysmenorrhea and as the value of body mass index and body fat percentages goes on increasing in females, the severity of primary dysmenorrhea also increased.

Mohapatra et al., [15] found out an association between BMI and dysmenorrhea among medical students. They found out that there is a positive correlation between dysmenorrhea and low BMI. They conclude a positive correlation between BMI and dysmenorrhea. 
Also, Widayanti and Widawati, [16] added that primary dysmenorrhea was $56 \%$ in women with BMI more than normal (overweight). They concluded that there was a correlation between the Body Mass Index (BMI) on primary dysmenorrhea. The effect of primary dysmenorrhea in overweight female students was 1.8 times higher than female students who had a normal Body Mass Index (BMI).

The current study was contradictory to Khodakarami et al., [5], as they found that the frequency and severity of dysmenorrhea was higher in the normal-weight group than other subjects. No relationship was seen between the severity and duration of dysmenorrhea with BMI. So in this study there was no significant association between BMI and dysmenorrhea.

\section{Regarding the effect of BMI on daily activities:}

The study findings revealed that there was no difference between groups in daily activities except for school absenteeism and social activity; there was a significant difference in school absenteeism existed between group (D) and the other groups, also social activity was highly influenced in both groups (D) and (A).

These results are in line with a study which highlight that educational performance of most of dysmenorrhic females $(60.4 \%)$ is affected due to class absentees, loss of concentration, lack of focus in exams and inability to do homework [17] .

Also, Gebeyehu et al., [3] found that more than two-thirds $(63 \%)$ of the respondents reported that they had encountered social withdrawal and decrease in academic performance $(51.4 \%)$. More than one-third $(40.9 \%)$ of the respondents experienced restrictions from day-to-day activities during their menstrual period and associated with this about $31.1 \%$ were absent from class and reported poor concentration $(43.4 \%)$. Nearly half $(42.7 \%)$ of the respondents reported they had altered sleeping pattern.

Also, Rafique and Al-Sheikh, [2] reported that $8.7 \%$ of their students reported college absenteeism due to severe dysmenorrhea, whereas $54.5 \%$ of the students mentioned that dysmenorrhea negatively affected their studies and daily activities.

The results of this study found that there was a significant difference in the NPRS between the four groups, there was a significant difference in the PPT between the four groups; both obese and underweight subjects had high pain intensity and low pressure pain threshold than normal weight and overweight subjects and there was no difference on daily activities between groups except for school absenteeism and social activity; there was a significant difference in school absenteeism existed between obese and the other groups, social activity was highly influenced in both obese and underweight.

\section{Conclusion:}

The difference in body mass index had an effect on primary dysmenorrhea; both obese and underweight subjects suffer from primary dysmenorrhea more than subjects with normal weight and overweight and there was no difference on daily activities except for school absenteeism and social activity had higher percentage in obese and underweight.

\section{References}

1- IACOVIDES S., AVIDON I. and BAKER F.C.: "What we know about primary dysmenorrhea today: A critical review". Human Reproduction Update, 21 (6): 762-78, 2015.

2- RAFIQUE N. and AL-SHEIKH M.: "Prevalence of primary dysmenorrhea and its relationship with body mass index". Journal of Obstetrics and Gynecology, 44 (9): $1773-8,2018$

3- GEBEYEHU M.B., MEKURIA A.B. and TEFERA Y.G. "Prevalence, impact, and management practice of dysmenorrhea among University of Gondar Students, Northwestern Ethiopia: A cross-sectional study". Int. J. Reprod Med., 1-8, 2017.

4- PAYNE L., RAPKIN A., SEIDMAN L., ZELTZER L. and TSAO J.: "Experimental and procedural pain responses in primary dysmenorrhea: A systematic review". Journal of Pain Research, 10: 2233-46, 2017.

5- KHODAKARAMI B., MASSOMI S., FARADMAL J., NAZARI M., SAADATI M., SHARIFI F. and SAKHABABAEI M.: "The Severity of Dysmenorrhea and its Relationship with Body Mass Index among Female Adolescents in Hamadan, Iran". Journal of Midwifery and Reproductive Health, 3 (4): 444-50, 2015.

6- McCARTHY H.D., MAFFIULETTI N., JUBEAU M., MUNZINGER U., BIZZINI M., AGOSTI F., COLE D.A., COLE T.J., FRY T., JEBB S.A. and PRENTICE A.M.: "Body fat reference curves for children". Int. J. Obes., 30: 598-602, 2006.

7- CHONG T.F., SER X.E., OOI L.K. and WONG L.S.: "Body constitution and dysmenorrhea: A study on university students in Malaysia". Oriental Pharmacy and Experimental Medicine, 18: 377-80, 2018.

8- YU W., GUAN F., FU L., LONG C. and YANG L.: "Disrupted physical pain sensation by social exclusion in women with dysmenorrhea". Journal of Pain Research, 11: 1469-77, 2018.

9- MACHADO P., PERRACINI M.R., CRUZ S.A., SILVA B.O., DRIUSSO P. and LIEBANO R.E.: “Microwave 
diathermy and transcutaneous electrical nerve stimulation effects in primary dysmenorrhea: Clinical trial protocol". Pain Management, 7 (5): 359-66, 2017.

10- POTUR D.C., BILGIN N.C. and KOMURCU N.: "Prevalence of Dysmenorrhea in University Students in Turkey: Effect on Daily Activities and Evaluation of Different Pain Management Methods". Pain Management Nursing, 15 (4): 768-77, 2014.

11- ZHANG Y.N., HUO J.W., HUANG Y.R., HAO Y. and CHEN Z.Y.: "Altered amplitude of low-frequency fluctuation and regional cerebral blood flow in females with primary dysmenorrhea". Journal of pain research, 12: 1243-50, 2019.

12- KAUR G., KAUR P. and HIMANI: "A Study of the relation of BMI with dysmenorrhea in adolescent girls". Int. J. Curr. Res. Med. Sci., 3 (8): 65-70, 2017.

13- HONG J.U., JONES M. and MISHRA G.D.: “A U-shaped relationship between body mass index and dysmenorrhea: A longitudinal study”. PLoS One J., 10 (7): 1-12, 2015.

14- SNEHALATA T. and MAHESH M.A.: "Relationship between body mass composition and primary dysmenorrhea". Indian J. Physiother. Occup. Ther., 10: 76-81, 2016.

15- MOHAPATRA D., MISHRA T., BEHERA M. and PANDA P.: "A study of relation between body mass index and dysmenorrhea and its impact on daily activities of medical students". Asian J. Pharm. Clin. Res., 9: 297-9, 2016.

16- WIDAYANTI L.P. and WIDAWATI P.R.: "Correlation Between Body Mass Index and Dysmenorrhea in Preclinical Female Students Aged 16-24". International Conference on Sustainable Health Promotion, 66-71, 2018.

17- DERSEH B.T., AFESSA N. and TEMESGEN M.: "Prevalence of dysmenorrhea and its effects on school performance: A crosssectional study". J. Womens Health Care, 6: 361, 2017.

\section{تآثير مؤشر كتلة الجسه على عسر الطمث الآولى البو والآنشطة اليومية فى المراهقات عيسرات}

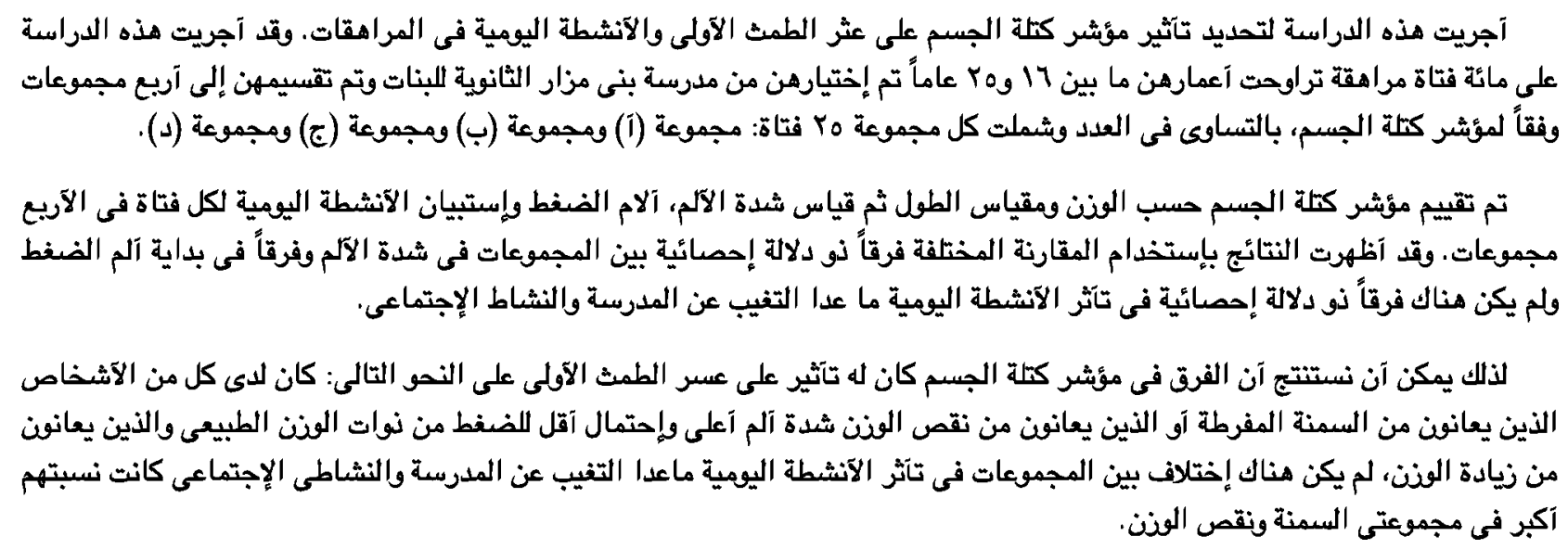

